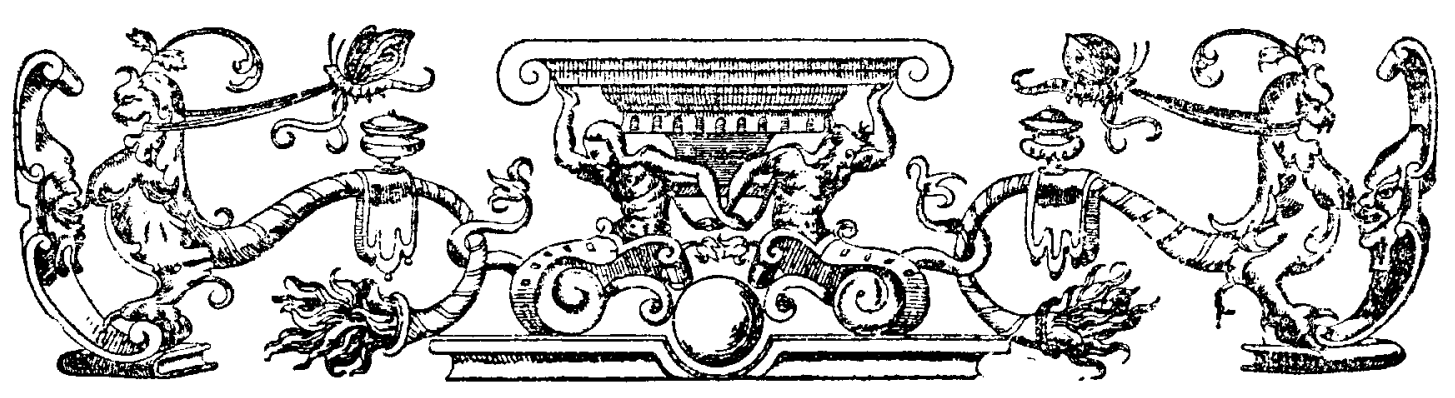

\title{
Een lijfpoëet van Prins Maurits
}

DOOR

\author{
PROF. DR. C. G. N. DE VOOYS.
}

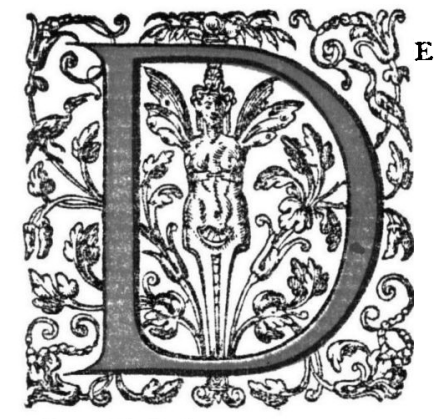

roem van FREDERIK HENDRIK werd in VONDEL's poëzie bezongen, maar dat de lof van Maurits door een Nederduits poëet uit zijn naaste omgeving niet minder uitbundig gebazuind is, bleef tot nu toe verborgen.

De eerste Januarie 1622 bood DAvid BECK Zijn Excellentie een eigenhandig geschreven bundel sonnetten aan, getiteld: De Trophéen off Zege-teckenen van den Nederlantscken Mars, waarin hij tegelijk proeven van zijn dichtkunst en van zijn ,penneconst" gaf. Dit manuscript bleef niet in het archief van de Oranjes, maar kwam na onbekende lotgevallen in het bezit van de uitgever J. MIJS te Tiel, die zo vriendelik was het tot mijn beschikking te stellen. 1)

DAvid BECK, de dichter van deze Mauritiade, was tot nu toe een onbekende. Omtrent zijn persoon vernemen wij uit zijn werk niet veel. Op het titelblad noemt hij zich: DAVID BECK VAN CöLN: hij behoort dus waarschijnlik tot degenen die om geloofsredenen in de Nederlanden de vrijheid kwamen zoeken,

1) Daarvoor betuig ik hem hierbij mijn dank. Het is te hopen dat het handschrift later in het bezit komt van de Koninklijke Bibliotbeek of in het huisarchief van de Oranjes, zodat het niet verloren gaat.

Oud-Holland 1919. 
want telkens doet hij zich als vurig Calvinist en papenhater kennen. Zijn Nederlands vertoont slechts hier en daar sporen van zijn buitenlandse afkomst 1): hij is dus in $162 \mathrm{I}$ reeds lang ingeburgerd in zijn nieuwe vaderland, dat hij met oprechte trots vereert. Uit de archieven blijkt alleen - gelijk een voorlopig onderzoek van Dr. H. E. VAN GELDER aantoonde - dat hij van een school. meestersfamilie is: zijn broer STEVEN in Den Haag en zijn broer HENDRIK te Rotterdam bekleedden dat ambt ook, en hij zelf wordt „Meester" genoemd. Wellicht blijkt later, wanneer hij de Hollandse bodem betrad. Hij zelf zegt alleen dat het in de kritieke jaren van de oorlog was:

Want als ick overdenck wat schrickelycker Vlam

Door Hollant golfde, doen ick eerst in Hollant quam

Myn hairen staen te Berg! 2)

Als rjonge man van Ceulen" ondertrouwde hij 30 Sept. 1618 in Den Haag met Roeltgen Lambrechtsdr. van Belle, uit Den Haag. Bij haar had hij twee dochters, SARA en RonLtge; de vrouw is kort voor 28 Sept. I 635 gestorven; hij zelf stierf vóór 17 Maart 164I. ${ }^{3}$ )

Stond deze Keulenaar in betrckking tot het stadhouderlik hof? Uit de opdracht vernemen wij alleen dat hij schuilde, "onder de wiecken van (Zijne) Excellenties Bescherminge", ạan wie zijn pen „van rechtswegen toekomt".

De geheele opdracht luidt:

\section{Doorluchtige Vorst! ende Genadige Heere:}

Naerdien wy door den meer als schuldigen Plicht waerdoor den Hemel soo veel hondert duysent Zielen aen Uwe Excellentie ende aen $U$ doorluchtig huys verbindet (met Liefde, danckbaerheyt, ende ootmoedigen dienst, voor soo mennigvuldige ende Oneyndige Weldaden van $U$ Excellentie bewesen door Raet ende daet aen dese Vereenigde Landen, Christi kercke, ende aen de Consten ende Letteren in deselve) schuldig syn Uwer Excellentie op te offeren ons Goet, Bloet ende alle ons Vermoogen, omme van deselve te disponeeren naer Syn gelieven als Uwe zeer Geneygde ende Ootmoedige dienst-schuldige Dienaeren: Soo zal het sonder Redenen ende een groote Vermeetentheyt schynen te zyn, datick

1) Men lette er op, dat versclueiden woorden en rormen, die ons als Cermanismen aandoen, omstreek $\mathbf{1 6 0 0}$ tot de Iitteraire taal, ool van zuiver-Nederlandse dichters behoren. Omsunst b.v. gebruikt ook VoNDEL; oon (= zonder) komt bij Spieguex voor; gewissen (= geweten) bij Hoofr. Vormen als nemet, verwinnet waren in de toenmalige gedichten zeer gebruikelik. Maar een vorm als mennig voor menig in stellig Keuls.

2) Poëme aen Syn Excellencie, biz, g.

3) Ook deze feiten dank ik aen de vriendeike mededeling van Dr. H. E. van Gedder. Mijn aanvankelike veronderstelling dat onze dichter de vader zou geweest zijn van de bekende schilder DAYID BECK, in 1621 te Delft geboren, bleek dus onjuist. 


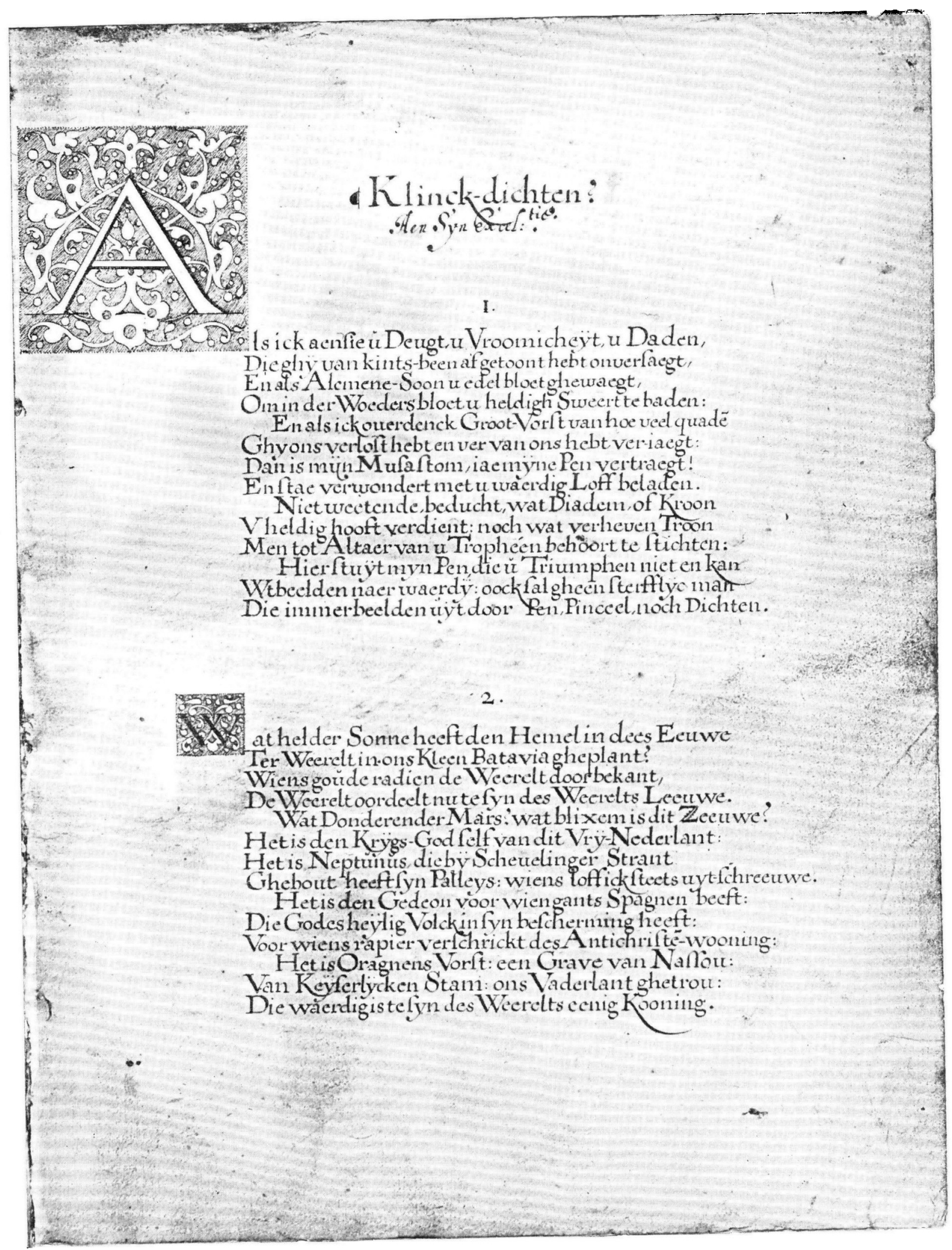

1. Eerste pagina der Klinckdichten van D. BECK, 162 I. 
Uwer Excellentie come vereeren (ende tot een Nieu-Faer opofferen) dese Uwe eygene Trophéen ofte in weynig Verskens U gantsche leven, loffelycke Deugden ende heldige daden, door de wyde Weerelt vermaert, beroemt ende gepresen: Naerdemaele den Dichter (die mede onder de wiecken van uwer Excellentiens Bescherminge schuylt, leeft ende sweeft, ende in zoete rust zyne Beroepinge waerneemet) syne Penne ende alle syn vermoogen Uwer Excellentie van rechts wegen toekomt. Nochtans, alsoo wy God den Heere (wiens Beelt Ghy alhier levende representeert) aengenaeme Offeranden doen van de Goederen die wy van Syner goedertierenheyt houden en ontfangen hebben, ende als onse eygene rekenen, sonder sig te vertoornen: soo achte ick niet te zullen doen tegen (ofte tot verminderinge) der Wetten des Algemeynen Plichts tot Uwer Hoogheyt, Uwer Excellentie hiermede aenbiedende ende dediceerende de ecrste Vruchten van mynen Arbeit zonder Arbeyt, hoewel Uwe Excellentie deselve (met my selven) sonder dat zig mogt toe eygenen met recht en reden. Ende waerlyck, wat zouden onse Pennen, de Miisen, de Wetten, het Recht in dese Nederlanden, met dese Nederlanden selve, sonder Uwe Excellentie (door Godes Genade) als hun eenig Element, Bron, Ziel, ende Leven? Ende waerdoor zouden de Mitsen (insonderheyt) oock beter Uwen Weldaden erkennen ende Roemen, dan door onse Poetelycke Gedichten?

Myn Heer! Onse Naerkomelingen (als de waerachtige ende oprechte Richters, van onse daden) verstaende door het waerachtig Verhael ende Getuygenisse van zulcke mennichte vreemde ende w theemsche Boecken, Uwer Excellentiens wonderlycke ende schier ongelooflycke deugden en Heroyxsche daden, zouden onse al te groote Ondanckbaerheyt ende Naerlatigheyt verfoeyen ende met reden mogen lasteren, soo wy naergelaten hadden door onse Pennen te betuygen de groote Genade die de Heere ons doet, te moogen leven onder de Voorspoedige ende Gelucksalige Regieringe van soodanigen Zege-rijckcn, Goedertierenen ende Godvruchtigen Prince, wiens Lof tot by den Antipoden gesongen wort. Doch sal Uwer Excellentie zonder twyffel vreemt vinden, dat ick (die geen Gebooren Nederlander ben, ende soo onervaren in de Tale, als onkundig inde Dicht-konst, zynde ter nauwer Noot eerst inder Muisen Schoole getreden) my vervoordere Uwe ZegeTeecken $n$ te dichten, een werck dat bet bitamen zoude de ghene die den hemel ende de Natuyre ryckelycker van Geest en Const begaeft hebben dan my, ende die door lange Oeffeninge overvlieger zyn in onse Nederlantsche Poësye. Nochtans (verhope ick) zal mynen goeden yver ende aengeboorene genegentheyt (die my hiertoe aengeraden, geport, ende schier gedwongen hebben) tot Uwer Excellentiens doorluchtig Huys, ende voor al tot Uwe Princelycke Persoon, my eenigsins verontschuldigen ende myne nederige Musa verschoonen. Ende indien hierinne 
maer het minste Streepken zy, dat Uwer Excellentie mogt behagen (alsoo ick vastelycken vertrouwe dat hier ende daer onder hondert Peerlen al eene ronde zal gevonden worden) soo zal ick meer als vernoegt zyn van myner Moeyte: Want soo dit myn Werck (buyten verwachten) Uwe Excellentiens gunste maer mag verwerven, soo en zal het zeive niet alleen gants Nederlant, maer al de wereit behagen en welgevallen, ende ick daerdoor te meer beweegt in mynen Eenvoudigen doch oprechten yver voort te gaen, ende dese Trophéen metter Tyt veeilicht te doen veranderen in eene Nederlantsche Mauritiade: Ten minsten sal ick hierdoor de Eere hebben, den eersten te zyn die door een Heroyxsch Poeme opgeweckt sal hebben onse Nederlantsche Poeeten (die den meesten dee 1 in de ydclheden van Venus, Cupido ende Bachus geconfyt zyn) om henluyden hunne nedere ende teere Myrten-Cranskens te doen veranderen in Croonen van Palmen en Laurieren. Ende zal my voor al een hertelycke vreugde zyn siende met goeden oogen aengezien het ghene ick met Eerbiedigheyt van goederherten hiermede legge voor de Voeten van Uwer Princelycker Excellentie tot een gering Nieu-Faer.

Hoog-Gebooren Vorst, ende Grootmoogende Prince. Ick bidde den Almoogenden $U_{w e r}$ Excellentie te nemen in syne heylige Bescherminge, ende te verleenen het verkrygen $U_{w e r}$ Princelycker weilschen met een seer Geluckzalig, voorspoedig, ende Zege-ryck Nieu-Jaer. Den Ien Januarius Ao 1622. In 's GravenHaghe.

\section{Uwer Excellentic Zeer Ootmoedigen dienaar D. BECK, Coloniensis.}

Nederiger kan het bijna niet, en dit praeludium, dat inderdaad de toon aangeeft waarop deze lofzangen gestemd zijn, is niet geschikt om hoge verwachtingen te wekken omtrent deze „eerstelingen". Maar tegen het einde blijkt dat achter deze nederigheid de eerzucht schuilt van een dichter, die het gevoel heeft meer te zijn dan een hofpoc̈et of gelegenheidsrijmer. Hij behoort niet tot het rederijkersgild, maar wil als renaissance-dichter met een Mauritiade de kunst van zijn tijdgenoten nieuwe wegen wijzen. Dan zal er eens een dichter opstaan die de roem van zijn vaderland verheerlikt in één groot Heldendicht. Zulk een dichter

Mag van haer heerlyckheit, Macht, Ryckdom, kryg en staet (Waerin dat Hollant nu sig self te boven gaet) Vry brengen aen den dag een schoon Bataviade. ${ }^{1}$ )

1) Sonnet 18. 


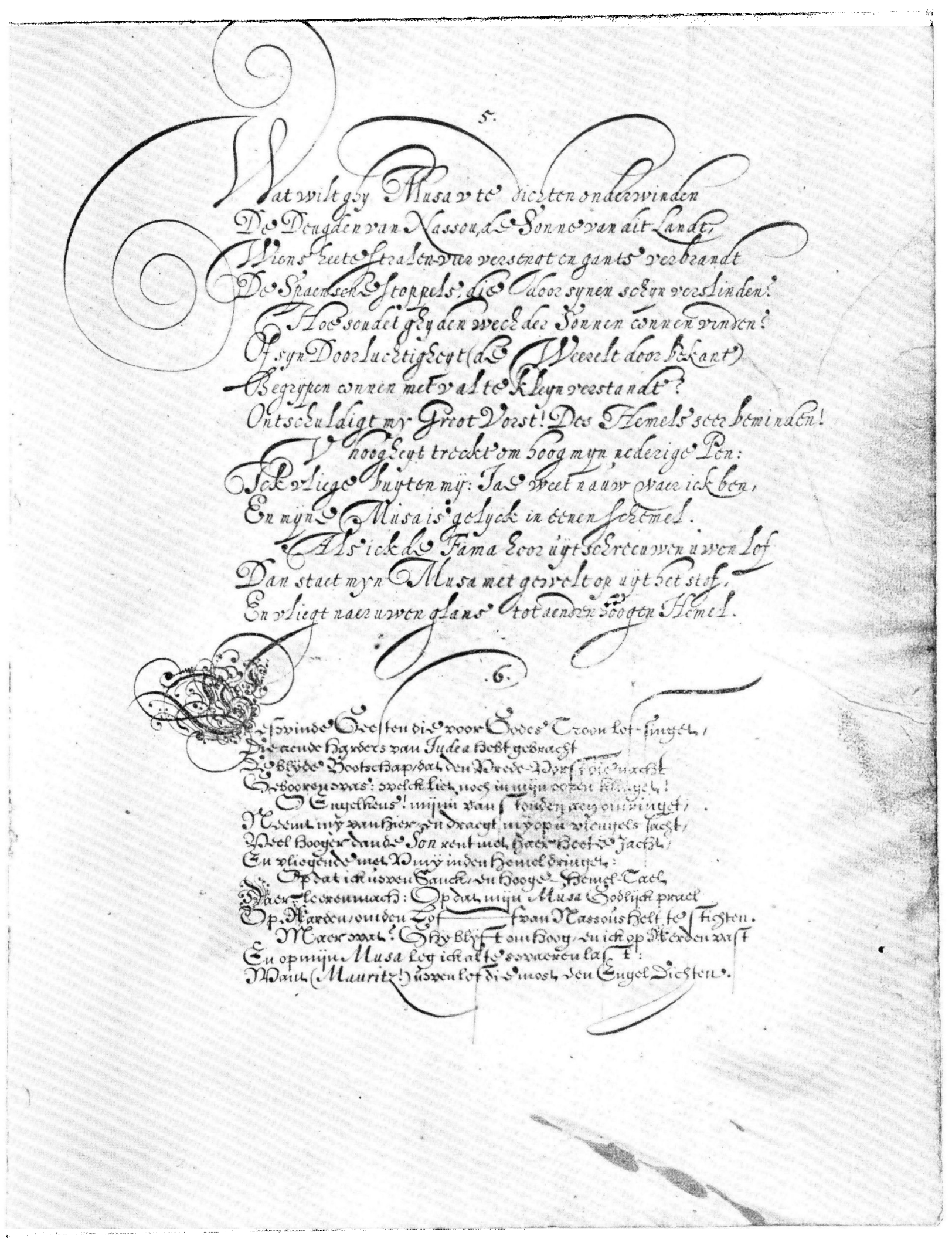

2. Specimen van de pennekunst van JAVIJ BECK, I62 r. 

Als tweede proeve geef $i k$ een sonnet van het twaalftal Opden vermasden Velt-slach by Nieupoort in Vlaenderen (No. 93-104)

100

Als nu Batazia met vrolycke Gesangen

Wtbromde sangryck tot des Hemels hoor Gebou

Den Viaemscher Zege des Achiles van Nassou,

En Vreugde-Vieren naer de Wolcken deden slangen:

Den Cardinael ontvlucht, den Admirant gevangen,

Den Spaenschen Cooning, met den Roomschen Bytebou,

Die huylden rasende, vol Gramschap, spyt en rou,

En spoelden in hun Tranen Aengesicht en wangen.

Hoe stont Italia met Oostenryck bedeest?

En sagen Spagnen aen, dat daer wel had geweest,

Doch niet licht wederom daer aen en docht te komen:

Als hebbende genoeg geproeft de Oorlogs-hant

Des Nederlantschen Mars, die haer had overmant

Soo heldig dat haer bloet by Nieupoort dreef als stroomen.

Geheel in de geest van zijil held toont hij zijn af keer van het Bestand, dat helaas geslaagde "vredesoffensief" van de Spanjaard. Het volgende sonnet waarin hij uiting geeft aan zijn spijt, is dus een eigenaardige tegenhanger van VONDEL's sonnet bij diezelfde gelegenheid, vol vreugde over de vrede.

$$
126
$$

Nassou doorsiende vast de loose Vosse-streken

Des argen $\operatorname{Lin} x$ (die vry van veynsen had Verstant,

Om ons te vangen door den Treíes of Bestant).

En mocht van Treves noch van Vrede hooren spreken.

Hy zag het Spaensche Paert oock vol Sinonen steken, (Ons dreygende met Moort, met Sweert, met Bloet en Brant. Die hy soo dickmaels inden Oorlog heeft vermant,

$E_{n}$ in een open Velt den $B e c k$ licht wist te breken.

Hy zag wat onheyl uyt den Treves komen mocht:

Hy wist wat Voordeel dat den Spagnart daer door socht,

Die door zoo langen Cryg ons royt en konde dwingen

Doch ziende dat den Schalck gants Hollant overwon,

Gaf hy den Pays aen die niet langer krygen kon,

En weeck een weynigh om te grooter spronck te springen.

Tot de beste en merkwaardigste gedeelten van de cyclus behoren de sonnetten over de godsdiensttwisten tijdens het Bestand. Ook hier kiest de dichter onvoorwaardelik de partij van MAURITS, en de verontwaardiging maakt hem welsprekend. Op tweeërlei wijzen brengt hij de ellende van de burgertwist in beeld: 
137

Hoe schricklyck holde korts den Nederlantschen Wagen. Als Jan van Spagnen aan den Dyssel-Boom noch sat? De Paerden (als verdroest) en hiclden spoor noch pat, Maar vlogen even dol door Steden, Dorpen, Hagen.

Den Voerman hadde doch daer in een goet behagen Hy was daer Oorsaeck van: Want hy elck Ros en Rat Betoovert hadde zelfs met Staens (Ghy weet wel wat) Oock scheen by regel-recht naar Spaagnen toe te jagen.

Nasson most van Syn Banck: Af most die oude Vracht, Want hy den Roomsihen kraem daer op te laden dacht, Die hem was aenbesteet voor Indiaensche knollen.

Maer als den dwaes nu docht aen Spagnens Grentz te syn, Ontmoeten hem $\mathrm{N}$ as sou die Toom Gorreel en Lyn Instucken sneet: Strax hiel den Wagen op van hollen.

$$
{ }_{13} 8
$$

Het Cooninglycke Wout van Hollant wijtgeruchtig, Wiens Trotse Boomen staen verheven hemel-hoog, Een tweede Paradys naer aller Menschen oog, Verheerlyckt door en met Orangens Boom doorluchtig:

Sag onlangs Truyrig uyt syn schaduwe voor-vluchtig

Der Philonelen Choor, vermits de Helle spoos

Een doodelijcke Pest, die door syn groente vloog, En bracht syn sangryck wilt ter Doot, of zieck, of zuchtig:

Het Levendige Groen zyns Boomgaerts gants verstierf Het schoon Geboomte met der Bloemen reuck verdierf: Oragnens Boom alleen blecí zeker van die Plagen,

Die Bloeyde (trots de Hel!) wiens stercken reuck te lest Verdreef uyt al het Wout de locht der helscher Pest,

Daer nu het Godlyck Choor Gods lof weer op gaet dragen.

Daarbij sluiten zich aan:

\section{3}

Wat helscher Vicr vloog door de Nederlantsche Steden? Hoe vlamden Hact en Nyt? Tweedrachtigheyt en list? Wat doller Raserny? Wat Acheronschen Mist

Verduysterde Gods Woort? Den Staet, het Recht en Reden?

Hoe quam den Tuymelseest soo schrickelyck gereden Door kerck, Stat-huyss en Hof, dier hy geen heeft gemist? Daer hy des Tweedrachts saet soo dick te saeyen wist, Dat syn Vergiftsche $P$ sst doorkroop meest al de leden. Hoe vocht men door Gelaet? Hoe dachtmen in het bloet Te baden (woedig) zyn verbittert heet Gemoet? Soe haest Gods suyver Woort hier was gemaeckt verdachtig?

Door onses Sinons list en syn half.Rooms gespoock? Het licht der Waerheyt doch verdreef dien heischen roock $\mathrm{Te}$ lest, en al syn Cracht wert door $\mathrm{N}$ a s s o u onkrachtig. 


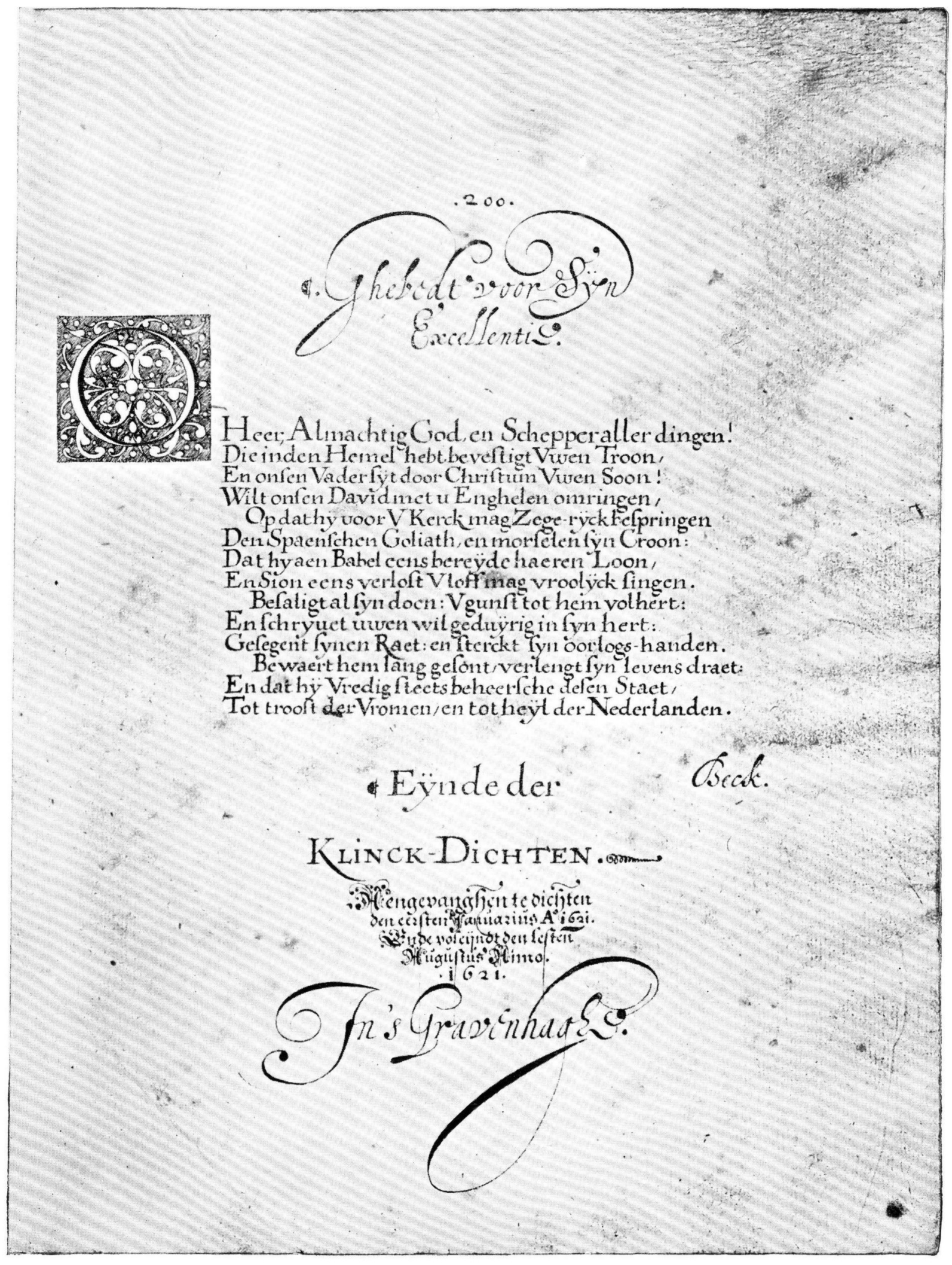

3. Slotpagina van de Klinckdichten van D. BECK, $162 \mathrm{I}$. 

144

Den Tuymelgeest die droeg de fackel vast in handen

Om onse Steden te vernielen kleyn en groot,

En rechte het Tooneel (voor Mars en voor de Doot)

Tot Inlants Oorlog in de Vrye Nederlanden :

De Pylen vast verknocht (door Eendrachts stercke Banden)

Van desen Vryen Staet ontbantmen sonder Noot,

En onder nieuwen Eet (wien dat het oock verdroot)

Wert menig duysent Man Gewapent in de Landen:

Men was Oragnen hier gants moede, wars, en sat:

Het Hemels Marna selfs dat walgden elck: Maer wat?

Men trachte weder hier den Spacnschen Room te krygen

Doch als dit quaet Gesnor aldus vast ging te werck,

Quam Mauritz (onvoorsiens) en smcetse uyt ons Perck

Soo dapper dat sy van dien spronck noch anxtig hygen.

In een geheel andere toonaard eert hij MAURITS om zijn goedertierenheid en vergevensgezindheid:

$$
\text { I } 52
$$

Gelyck een Vader, die tot gramschap is ontsteken

Door syn rebellig kint, syn Toornigheyt verbyt:

En door Vermaeningen en goetheyt zig bevlyt

Om syn Moetwillig kint te winnen door soet spreken:

Verdragende ten deel syn leelycke Gebreken,

En (toonende berou) sijn feylen scheldet quyt,

Niettegenstaende den voorleden smaet en spyt,

Waervan hy sich door straf (met reden) mochte wreken.

Alsulck een liefde heeft $\mathrm{M}$ a uritius gretoont

Aan sco veel steden, en quaetwillige verschount,

Die in Batavia trots tegen hem opstonden:

Niet eens gedenckende hun feylen, hoon, en smaet,

Alleen bekommert hoe de Pylen van den Staet

Door Eendrachts stercken Bant maer mochten zijn herbonden.

Wanneer eindelik het verwenste Bestand eindigt, dan juicht de dichter over de Vernieuwinge van den Oorloogh:

164

Juygt vreugdig Hollants Volck! O Zeeuwen doet nu branden

U Vreugde-Vieren! nu het lang-gehaet Bestant

Voor duysent plagen wort gedreven uyt het Lant,

Waerdoor Oragnens Leeu geraeckt uyt syne Banden.

Springt op van vroolyckheyt Vereende Nederlanden!

U Goude Tyden zyn nu weder voor der hant:

Dien helschen Treves steeckt den Moort: dienSpaenschen Bant

Breeckt huyden gants in tween : klopt vreugdig in $U$ handen! 
Bedruckt Bohemen! haelt u hert nu weder op! Ghy droeve Paltz! en hout geen droef heyt in den krop! Het zal wel syn, hebt Moet, en wilt op God vertrouwen.

Ick zie, ick zie alrec den $P a u s$ beteutert staen Met syn gebroet: Ick zie den Arent vast begaen Met Spagnen, om de Macht te keeren van Nassouwen.

Daarbij sluit zich aan :

$$
\text { I } 66
$$

Ghy Hemels-dochter! O ghy allersoetste Vrede!

Godinne! steets versclt (tot pronck van Uwen Staet)

Met Voorspoed, Vrougde, Rust, en Ryckdoms overmaet,

Met liefd en Eendracht $U$ den Hemel oyt bekleede:

De weerelt wenscht om $U$ en Hollant noemt U: Wreede!

Jae Zeelant $\mathrm{U}$ vervloeckt, en clck $\mathrm{U}$ hier versmaet:

Om dat den Satan in den Nederlantschen Staet

In Vrede-Tyt des Twist en Tweedrachts Wapens smeede.

Maer daerentegen, als $\mathrm{N}$ a s s o $\mathrm{u}$ sig moedig sloeg

Met Spagnen, Liefde, rust, en Eendracht hun toeloeg:

In Oorlog seker, en in Vrede schier Verlooren

Hola. ick doole! want den Treues: valschlyk draegt

Den Naem van Vrede: die wort heden weer verjaegt,

Op dat (door Enion) Ghy hier eens wort herbooren

$\mathrm{Nu}$ de listen van Spanje en Rome verijdeld zijn, kunnen de ouden vijanden weer openlik bestreden worden. Opmerkclik is het, hoe deze dichter in zijn felle haat tegen Rome zijn Held idealiseert tot de kampioen voor het ware Geloof: tijdens "den Arminiaenschen handel" heeft hij het verdedigd tegen "JAN VAN SPANJE", of - zoals hij later heet - "OLDEN JAN", die met Spanje en Rome heulde; na het Bestand roept hij hem toe: "Vaert voort, O groote siel! wilt Roma kloeck bestryden" (Sonnet 170). Wanneer hij het over de Roomse "afgodery" heeft, dan slaat hij de toon aan van de oude Geuzentijd. Bij de herdenking van de martelaren der vrijheid zegt hij dat ze "wreetlyck syn verdaen, omdat zy Meel-is niet en wilden bidden aen" (Sonnet $5 \mathrm{I}$ ), een bekende Geuzen-woordspeling, die terugkeert in het Poëme aen Syn Excellencie (blz. 6), waar hij spreekt over "De Roomsche Cramery van Melis Papen Wet". Maar het toppunt wordt bereikt in het volgende scheldsonnet op Rome:

169

Ghy seven-Bergsche Stat! Des Weerelts Cooninginne!

Veelhoofdig Monsterdier! des Antichristes Stoel!

Vervloeckte Babilon! Afroderyen Poel!

O Grouwelyck Bordeel der Sodomytscher Minue!

Nest der Verradery! der Vroomen Moorderinne!

Eerloose Hoere! Bron der dwaling! Geylheyts doel

Pest der Gerechtigheyt! Des Wcerelts Vorsten Boel!

Der Moordenaeren Burg! O wreedo Tygerinne! 
Ghy Moeder van de Pracht! O dochter van de Hel!

Ghy Voetster alles Quaets! Paleys van Fesabel!

Al troetelt Ghy U selfs, en roemt doorgaens op Stagnen:

Beklaegt, beschreyt, besucht, beweenet Uwen val!

Hy springt vast uyt het Wout die U Oordeelen sal,

Den Cooninglycken Leeu, den Neve van Oragnen.

Als laatste proeve uit deze sonnettenreeks geef ik er een, waarin de trots spreekt op zijn nieuwe Vaderland, dat ook in wetenschappen en kunsten door MAURITS tot bloei gebracht is:

I 86

Soo onse Landen syn te kleyn in onse Dagen

Om onser kinderen ontallyck groot Getal

Te dragen nu voortaen, soo datmen over-al

De Zee moct kruyssen om nieu Landen te bejagen:

Sou onse Steden nu van Kyckdom overwagen

En syn met recht vermaert rontom des Weerelts Bal,

Als Wapen-kamers, of des Weerelts Wapenstal,

En kleynood-kisten, die des Weerelts Schatten dragen.

Soo Romen en Athenen nu in Hollant zyn,

Soo de Geleertheyt nu bewoont den Leyd-schen Rhyn,

Soo Nederlant is vol van Treflycke Poeeten,

En soo de Musen hier alleene houden hof,

Daer van doorluchtig Vorst! komt $U$ alleen den lof,

Dien vry verhoogen Heyns en Catz, twee nieu Planeeten.

In sonnet $191-192$ betreurt de dichter dat zijn Ifeld geen zoon zal nalaten, die zijn taak kan overnemen:

O! mochten wy (Groot Vorst!) noch onsen wensch verwerven!

En sien U Hoogheyt met een funo eens gepaert

Die eenen Jongen Prins (naar Uwen Vroomen Aert)

Tot troost van onsen Staet, van U Bloet, mogt beerven!

Dan volgen enige sonnetten $O p$ het Conterfeytsel van Syn Excellentie, nl. op zijn beeltenis door MIEREvelt, en ten slotte het Ghebedt voor Syn Excellencie, dat men in reproduktie lezen kan.

Het Poëme aen Syn Excellencie is een samenvatting in epiese vorm, waarschijnlik een poging om de Mauritiade te schetsen, die hij volgens zijn Opdracht eens hoopte te dichten. Ook de alexandrynen van dit gedicht zijn niet onverdienstelik. Ten bewijze een kort fragment (blz. 3):

Groot Vorst! Ick mogt veel eer den blaeuwen Oceaen

Met myner handen hol geheel uyt scheppen gaen:

Of al de sandekens langs syne Stranden tellen,

Eer ick $U$ daden op een reye mogt vertellen:

Wiens ontellyck Getal in hondert Boecken krielt,

Waer voor myn Musa gants demoedig nederknielt: 
Te vreden hier alleen dit weynig aen te roeren, En op haer Wieckskens door gants Nederlant te voeren. Der Vreemder Helden rey (ontelbaer) dien de Doot De Vracht betalen liet in Carons Ouden Boot, Om over Acheron naer Plutons Ryck te vaeren, En aen Syn Borgery met Traenen te verklacren De Oorsaeck hunnes Doots, en Uwer Armen Cracht, Wiens Blixem nimmermeer en schiet uyt hun gedaci.t Die weeten wat $U$ hant vermag, die Hollants handen (Vrywillig) ketent, en gesloten hout in Banden. En die het Machtig Heyr van dit Vry-Nederlant Nu geeft den lossen Toom, dan houdet in den Bant. Gelyck men somtyts ziet in Hollants duynen sandig, Of in U Haegsche Bos (zeer lieflyck en Waerandig) Dat eenig Jager naer het Wilt Syn honden lost, En achter aen door sant, door struyck en Telgen trost, Tot dat hy eyndelyck, naer synes herts verlangen, De Hinden, Hasen of Coonynen ziet gevangen: Den Jager schort de jacht, en onder syne Wet Ten lesten wederom elck van syn Winden zet: En vangt de Vangers, die sig willig laten binden Om byten noch gebas als syn gehoorsam Winden. So siet men onder U Beleyt des Oorlogsdans: Daer menig Batazier, Duyts, Engels, Sihot en Frans, (Wiens hoofden gelauriert met Trotse Zege-Cranssen) Als vroome Helden steets naer Uwe Wetten danssen: Met soo veel duysenden Soldaten Cloeck en Trou, Die steets hun Eere gaen opdraegen aen Nassou:

En heldig voor Gods Woort en onse Vryheyt stryden, Om haest den Antichrist te brengen in het lyden.

Andere geschriften van DAviD BECK vond ik nergens vermeld. Wellicht is deze eersteling ook zijn laatste dichtwerk geweest, maar ook door deze ene sonnettenbundel heeft de Haagse hofpoëet aanspraak op een bescheiden plaatsje onder de lange rij van dichters uit onze vroege renaissance, de voorlopers van de Gouden Eeuw.

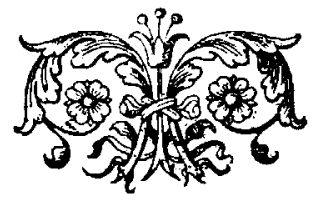

